\title{
ADVERSE EVENTS FOLLOWING LUMBAR SPINE FUSION: THE IMPACT OF DIABETES MELLITUS
}

(D) Khalid Alsaleh

\author{
King Saud University Department of Orthopedic Surgery, Riyadh, Saudi Arabia
}

\begin{abstract}
Objective: Spinal surgery is becoming increasingly popular, but its complications cause substantial morbidity and mortality. Diabetes mellitus is prevalent in patients undergoing lumbar fusion surgery, yet the literature is divided on whether they are prone to a higher complication rate and worse outcomes. The aim of this study is to investigate the complication rates in patients undergoing elective lumbar fusion surgery and its relationship to diabetes mellitus and other potential risk factors.

Materials and Methods: A retrospective review of all adult patients undergoing instrumented lumbar fusion surgery in the past two years was performed. Demographic and clinical data were collected, and diabetic patients were compared with non-diabetic controls. Statistical analysis was performed to test for the significance of any difference, and multiple regression analysis was then done to assess the strength of this significance.

Results: Eighty patients were included in the study, 24 (30\%) of whom were diabetic. Diabetic patients were older, had more comorbidities, shorter fusions, less blood loss, more complications but similar pain control and length of stay compared to non-diabetic patients. Diabetes was found as an independent significant predictor of adverse events, yet the other factors were not found.

Conclusion: Patients with diabetes mellitus have a higher risk of infection and other complications following instrumented lumbar fusion. Although maintaining good glycemic control is paramount, the higher risk necessitates close postoperative observation and extra care in the long term.

Keywords: Spine surgery, diabetes mellitus, complications
\end{abstract}

\section{INTRODUCTION}

The last two decades have brought about a substantial increase in lumbar spine fusion surgery globally ${ }^{(1-3)}$. Improved understanding of lumbar pathology and biomechanics led to improved outcomes when compared to nonoperative treatment ${ }^{(4,5)}$. An aging population and increasingly more complex procedures lead to concerns of higher complication rates in some instances ${ }^{(6,7)}$.

A significant percentage of spine surgery patients suffer from diabetes mellitus (DM), up to $25 \%{ }^{(8)}$. Numerous studies have looked into the association of DM with clinical outcomes following lumbar fusion surgery, and a clear association was found in most ${ }^{(9,10)}$. Patients with DM had worse clinical outcomes and were burdened with a higher rate of adverse events $s^{(8,11)}$. This realization caused an increased emphasis on tight control of DM prior to spine surgery, with clinical pathways incorporating a normal $\mathrm{HgA} 1 \mathrm{C}$ as a precondition for considering elective lumbar spine surgery ${ }^{(12)}$. The assumption was that euglycemic patients should have similar outcomes to non-diabetic patients, as was stipulated in some published results ${ }^{(13,14)}$. The author noticed that complication rates were still more prevalent in diabetic patients, regardless of how controlled the serum glucose is. The goal of this study was to investigate the complication rates in patients undergoing elective lumbar fusion surgery and to investigate the modifiable risk factors associated with its incidence.

\section{MATERIALS AND METHODS}

The institutional research ethics board approval (21/0034/IRB) was obtained prior to the collection of the data. A retrospective chart review of all patients undergoing elective thoracolumbar fusion surgery in our institution from January 2019 to the end of December 2020 was performed. All these patients went through a pre-anesthesia evaluation that included confirmation of normal serum glucose (4.4-7.8 mmol/L) and hemoglobin A1c levels (<7.5\%) for all patients suffering from DM. All patients that did not fulfill this condition had their procedure delayed until their blood sugar was well controlled. Data collected included demographics and numerous clinical data. That included the American Society of Anesthesiologists physical Status Classification System, the number of levels fused, the estimated 
turkishspine

blood loss intraoperatively, the length of anesthesia, the first day of mobilization out of bed, the length of inpatient stay, the numeric pain score on the day of discharge, the presence of any complications, the serum glucose level on the day of discharge (for diabetic patients) and patient's status when it comes to DM. Short-term follow-up was available for all patients (up to one year). All data was anonymized, coded, and tabulated electronically on a password-secured computer. The t-test and the Mann-Whitney test were used for the analysis of continuous data, while the chi-square test was used for the analysis of categorical data. Regression analysis was performed for the relevant variables to assess the strength of their association with the primary outcome of postoperative complications. All analysis was performed on SPSS version 27 software (IBM Corp, Armonk, NY, USA). All procedures followed were in accordance with the ethical standards of the responsible committee on human experimentation (institutional and national) and with the Helsinki Declaration of 1975, as revised in 2000.

\section{RESULTS}

Eighty patients were included in the study cohort, twenty-four out of which (30\%) had DM. The demographic and clinical data are presented in Table 1.
The incidence of patients who had complications was $8.8 \%$ $(n=7$ patients). The complications were as follows: six wound infections requiring reoperation, one deep vein thrombosis, and one urinary tract infection (one patient had two complications). Univariate analysis showed that DM was significantly associated ( $p=0.026$ ) with the incidence of complications (odds ratio $=7,105,95 \%$ confidence interval: 1.271-39,725). Multiple regression analysis revealed that DM alone was significantly associated with the development of complications (Table 2). There were no deaths, and all patients left the hospital to their residence, mobilizing independently with minimal need for assistance.

\section{DISCUSSION}

DM is a global epidemic, causing substantial morbidity and mortality ${ }^{(15,16)}$. The continued rise of the incidence of DM is unequal, affecting developing countries at a higher rate and posing a significant challenge to the healthcare systems ${ }^{(17,18)}$. The pathophysiology is complex, but it has been proposed that glycosylation of tissue leads to irreversible fibrosis and angiogenesis resulting in end-organ damage ${ }^{(19)}$. The link between DM and surgical complications- infection particularlyhas been repeatedly reported on ${ }^{(20,21)}$. The first series reporting

Table 1. Demographic and clinical information of the study sample

\begin{tabular}{|c|c|c|c|}
\hline & Diabetic $(n=24)$ & Non-diabetic $(n=56)$ & p-value \\
\hline Age (SD) & $62.9(13.3)$ & $38.7(18.1)$ & 0.001 \\
\hline Female sex, n (\%) & $18(75)$ & $36(64)$ & 0.225 \\
\hline ASA class, $n$ (\%) & & & 0.018 \\
\hline 1 & 3 & 23 & \\
\hline II & 14 & 27 & \\
\hline III & 7 & 6 & \\
\hline Number of levels (SD) & $1.54(1)$ & $4.34(4.44)$ & 0.003 \\
\hline EBL in ml (SD) & $302(128)$ & $417(267)$ & 0.048 \\
\hline LOA in minutes (SD) & $246(74.9)$ & $275(96.7)$ & 0.196 \\
\hline Days to mobilize (SD) & $1.58(1)$ & $1.79(1)$ & 0.246 \\
\hline NPS on DOD (SD) & $1.87(1.74)$ & $1.86(1.29)$ & 0.972 \\
\hline RSG on DOD in mmol/L (SD) & $7.8(1.8)$ & N/A & N/A \\
\hline LOS in days (SD) & $5.54(4.3)$ & $4.77(1.7)$ & 0.252 \\
\hline Complications, n (\%) & $5(21)$ & $2(3.6)$ & 0.012 \\
\hline
\end{tabular}

SD: Standard deviation, EBL: Estimated blood loss, LOA: Length of anesthesia, NPS: Numeric pain score, DOD: Day of discharge, RSG: Random serum glucose, LOS: Length of admission

Table 2. Multiple regression analysis of factors associated with complications

\begin{tabular}{llll}
\hline & Odds ratio & $95 \%$ confidence interval & p-value \\
\hline DM & 13.21 & $1.175-148,452$ & 0.037 \\
\hline ASA & 1.166 & $0.316-4,299$ & 0.818 \\
\hline EBL & 1.003 & $0.999-1.007$ & 0.146 \\
\hline Number of levels & 0.997 & $0.714-1.393$ & 0.987 \\
\hline
\end{tabular}

DM: Diabetes mellitus, ASA: American Society of Anesthesiologists, EBL: Estimated blood loss 
on this issue was by Simpson et al.(22) in 1997. Reporting on 62 lumbar fusion cases performed in the 1980s, longer hospital stay, delayed wound healing, and poor clinical results were noted in the DM group. Of note is that the mean serum glucose in that series was $10 \mathrm{mmol} / \mathrm{L}$ (6-14), which shows that there was no strong control on DM for that cohort. The second study was published by Glassman et al. ${ }^{(23)}$. It involved a retrospective review of 94 cases against a matched control group. Again, complication rates were higher in the DM group (53\% vs. $21 \%$ ). Subgroup analysis for multi-level fusions showed a higher complication rate, a finding that was not confirmed in our series. In fact, the diabetic group had less blood loss and shorter fusion in our study yet still had more complications. That may be attributed to the employment of less invasive approaches in the diabetic patients to reduce complication rates. Cho et al.(24) reported on the impact of DM on outcomes in spinal deformity cases. They reported on a cohort of 23 adult deformity cases with DM utilizing a matched case-control design. They did not find any difference between hey two groups and attribute that to the matching by age, sex, body mass index (BMI), and operative details. This was possible as they selected the control group from over 5000 such cases in their database. Our study did not match for age or comorbidity, but regression analysis confirmed that DM alone has the strongest association with complication occurrence. Shortly after, Takahashi et al.(25) published their series of 41 patients with DM who underwent lumbar fusion. They compared their cohort with 124 non-diabetic patients and were the first to link a higher hemoglobin A1c (HgA1C) level with poor outcomes. They also found that patients who have had diabetes for more than 20 years had worse outcomes. Sharma et al.(26) published their series in the same year and contradicted Takahashi et al. ${ }^{(25)}$ by confirming a higher complication rate in DM patients ( $29 \%$ vs. $13 \%)$. The rest of their clinical data was not different between the groups except for the length of stay, which was higher in the DM group ${ }^{(26)}$. Their results are very close to the findings from this current study, especially noting that they reported relatively good glycemic control -measured by HgA1C- for their DM cohort. Golinvaux et al.(27) made a distinction between non-insulin-dependent DM (NIDDM) and insulin-dependent DM (IDDM). They reported that an increase in complication rates was found in the IDDM group, and that the complications themselves were more severe. The NIDDM group did differ in some clinical data-such as BMI-and in none of the groups was there any mention of glycemic control. We did not make any distinction based on insulin dependence, as the literature supports the notion that good glycemic control is paramount regardless of the type of $\mathrm{DM}^{(28)}$. Guzman et al.(29) addressed the issue of glycemic control in their study. A direct comparison of controlled DM and uncontrolled DM patients undergoing lumbar spine surgery showed that diabetic patients had a higher complication rate in general, and uncontrolled DM led to a longer hospital stay and higher mortality.

\section{Study Limitations}

This study had some limitations, such as a retrospective design, short-term follow-up, and a relatively small sample size. Nevertheless, the data comparison and analysis clearly showed that -regardless of glycemic control and despite smaller operations and less blood loss-diabetic patients are more prone to adverse events, and as such extra care needs to be taken in their postoperative clinical follow-up.

\section{CONCLUSION}

Patients with DM have a higher risk of infection and other complications following instrumented lumbar fusion. Although maintaining good glycemic control is paramount, the higher risk is present regardless.

\section{Ethics}

Ethics Committee Approval: The institutional research ethics board approval (21/0034/IRB) was obtained prior to the collection of the data.

Informed Consent: Retrospective study.

Financial Disclosure: The author declared that this study received no financial support.

\section{References}

1. Kobayashi K, Ando K, Nishida $\mathrm{Y}$, Ishiguro N, Imagama S Epidemiological trends in spine surgery over 10 years in a multicenter database. Eur Spine J. 2018;27:1698-703.

2. Martin BI, Mirza SK, Spina N, Spiker WR, Lawrence B, Brodke DS Trends in lumbar fusion procedure rates and associated hospital costs for degenerative spinal diseases in the United States, 2004 to 2015. Spine (Phila Pa 1976). 2019;44:369-76.

3. Deyo RA, Gray DT, Kreuter W, Mirza S, Martin BI. United States trends in lumbar fusion surgery for degenerative conditions. Spine (Phila Pa 1976). 2005;30:1441-5; discussion 1446-7.

4. Abdu WA, Sacks OA, Tosteson ANA, Zhao W, Tosteson TD, Morgan TS, et al. Long-term results of surgery compared with nonoperative treatment for lumbar degenerative spondylolisthesis in the Spine Patient Outcomes Research Trial (SPORT). Spine (Phila Pa 1976). 2018;43:1619-30.

5. Lurie JD, Tosteson TD, Tosteson A, Abdu WA, Zhao W, Morgan TS, et al. Long-term outcomes of lumbar spinal stenosis: eight-year results of the Spine Patient Outcomes Research Trial (SPORT). Spine (Phila Pa 1976). 2015;40:63-76.

6. Daubs MD, Lenke LG, Cheh G, Stobbs G, Bridwell KH. Adult spinal deformity surgery: complications and outcomes in patients over age 60. Spine (Phila Pa 1976). 2007;32:2238-44.

7. Drazin D, Shirzadi A, Rosner J, Eboli P, Safee M, Baron EM, et al. Complications and outcomes after spinal deformity surgery in the elderly: review of the existing literature and future directions. Neurosurg Focus. 2011;31:E3. doi: 10.3171/2011.7.FOCUS11145.

8. Kim CH, Chung CK, Shin S, Choi BR, Kim MJ, Park BJ, et al. The relationship between diabetes and the reoperation rate after lumbar spinal surgery: a nationwide cohort study. Spine J. 2015;15:866-74.

9. Appaduray SP, Lo P. Effects of diabetes and smoking on lumbar spinal surgery outcomes. J Clin Neurosci. 2013;20:1713-7.

10. Luo W, Sun RX, Jiang H, Ma XL. The effect of diabetes on perioperative complications following spinal surgery: a meta-analysis. Ther Clin Risk Manag. 2018;14:2415-23 
turkishspine

11. Epstein NE. Predominantly negative impact of diabetes on spinal surgery: a review and recommendation for better preoperative screening. Surg Neurol Int. 2017;8:107.

12. Chakravarthy VB, Yokoi H, Coughlin DJ, Manlapaz MR, Krishnaney AA. Development and implementation of a comprehensive spine surgery enhanced recovery after surgery protocol: the Cleveland Clinic experience. Neurosurg Focus. 2019;46:E11. doi: 10.3171/2019.1.FOCUS18696.

13. Browne JA, Cook C, Pietrobon R, Bethel MA, Richardson WJ. Diabetes and early postoperative outcomes following lumbar fusion. Spine (Phila Pa 1976). 2007;32:2214-9.

14. Satake K, Kanemura T, Matsumoto A, Yamaguchi H, Ishikawa $Y$. Predisposing factors for surgical site infection of spinal instrumentation surgery for diabetes patients. Eur Spine J. 2013;22:1854-8.

15. Engelgau MM, Geiss LS, Saaddine JB, Boyle JP, Benjamin SM, Gregg $\mathrm{EW}$, et al. The evolving diabetes burden in the United States. Ann Intern med. 2004;140:945-50.

16. Mokdad AH, Ford ES, Bowman BA, Nelson DE, Engelgau MM, Vinicor F, et al. Diabetes trends in the US: 1990-1998. Diabetes Care. 2000;23:1278-83.

17. Lozano R, Naghavi M, Foreman K, Lim S, Shibuya K, Aboyans V, et al. Global and regional mortality from 235 causes of death for 20 age groups in 1990 and 2010: a systematic analysis for the Global Burden of Disease Study 2010. Lancet. 2012;380:2095-128.

18. 18. Roglic G. WHO Global report on diabetes: A summary. Int J NonCommun Dis. 2016;1:3.

19. Twigg SM, Chen MM, Joly AH, Chakrapani SD, Tsubaki J, Kim H-S, et al. Advanced glycosylation end products up-regulate connective tissue growth factor (insulin-like growth factor-binding proteinrelated protein 2) in human fibroblasts: a potential mechanism for expansion of extracellular matrix in diabetes mellitus. Endocrinology. 2001;142:1760-9.

20. Akiboye F, Rayman G. Management of hyperglycemia and diabetes in orthopedic surgery. Curr Diab Rep. 2017;17:13.
21. Wang J, Chen K, Li X, Jin X, An P, Fang Y, et al. Postoperative adverse events in patients with diabetes undergoing orthopedic and general surgery. Medicine (Baltimore). 2019;98:e15089. doi: 10.1097/ MD.0000000000015089.

22. Simpson JM, Silveri CP, Balderston RA, Simeone FA, An HS. The results of operations on the lumbar spine in patients who have diabetes mellitus. J Bone Joint Surg Am.1993;75:1823-9.

23. Glassman SD, Alegre G, Carreon L, Dimar JR, Johnson JR. Perioperative complications of lumbar instrumentation and fusion in patients with diabetes mellitus. Spine J. 2003;3:496-501.

24. Cho W, Lenke LG, Bridwell KH, Dorward IG, Shoda N, Baldus CR, et al. Comparison of spinal deformity surgery in patients with non-insulindependent diabetes mellitus (NIDDM) versus controls. Spine (Phila Pa 1976). 2012;37:E978-84. doi: 10.1097/BRS.0b013e31824edf42.

25. Takahashi S, Suzuki A, Toyoda H, Terai H, Dohzono S, Yamada K, et al. Characteristics of diabetes associated with poor improvements in clinical outcomes after lumbar spine surgery. Spine (Phila Pa 1976). 2013;38:516-22.

26. Sharma A, Muir R, Johnston R, Carter E, Bowden G, Wilson-MacDonald J. Diabetes is predictive of longer hospital stay and increased rate of complications in spinal surgery in the UK. Ann R Coll Surg Engl. 2013;95:275-9.

27. Golinvaux NS, Varthi AG, Bohl DD, Basques BA, Grauer JN. Complication rates following elective lumbar fusion in patients with diabetes: insulin dependence makes the difference. Spine (Phila Pa 1976). 2014;39:1809-16.

28. Diabetes Canada Clinical Practice Guidelines Expert Committee, Imran SA, Agarwal G, Bajaj HS, Ross S. Targets for Glycemic control. Can J Diabetes. 2018;42(Suppl 1):S42-6.

29. Guzman JZ, latridis JC, Skovrlj B, Cutler H, Hecht AC, Qureshi SA, et al. Outcomes and complications of diabetes mellitus on patients undergoing degenerative lumbar spine surgery. Spine (Phila Pa 1976). 2014;39:1596. 